\title{
Effects of metritis on stall use and social behavior at the lying stall
}

\author{
J. Lomb, D. M. Weary, K. E. Mills, and M. A. G. von Keyserlingk ${ }^{1}$ \\ Animal Welfare Program, Faculty of Land and Food Systems, University of British Columbia, 2357 Mall, Vancouver, B.C., Canada V6T 1Z4
}

\begin{abstract}
Metritis in dairy cows has been associated with changes in behavior at the feed bunk, but little is known about the effects on behavior at the lying stall. The aim of this study was to investigate stall use by primiparous dairy cows diagnosed with metritis, specifically time spent in the stall, social interactions at the stall, and lying-related behaviors. After parturition, primiparous cows were housed in a mixed-parity pen with a constant group size of 20. Cows had access to 12 electronic feed bins, 2 electronic water bins, and 24 lying stalls. Four cameras installed above the experimental pen allowed for observation of cows in the feeding and lying area. Every $3 \mathrm{~d}$ after parturition, cows were examined for metritis by evaluation of the visual appearance and olfactory character of vaginal discharge. Cows diagnosed with metritis $(\mathrm{n}=16)$ were compared with healthy individuals (i.e., cows without metritis or other clinical disease, $\mathrm{n}=16$ ). Healthy individuals were selected based on data availability, body weight, and calving date and, based on these criteria, paired with metritic cows. Video of the $3 \mathrm{~d}$ before diagnosis $(\mathrm{d}-3$ to $d-1$ ) in the metritic animals (and video from the corresponding days in milk for paired healthy cows) were used to measure behavior. Behaviors assessed included those in the stall (lying, perching, and standing fully in the stall), social behaviors (when a cow either displaced or was displaced by another cow; i.e., actor and reactor replacements), and lying-related behaviors (including visits when the cow entered and left the stall without lying down, aborted lying events when behaviors indicative of the onset of a lying bout were not followed by the cow lying down, and latency to lie down, defined as the time between an aborted lying event and the first lying bout). Cows with metritis spent more time standing fully in the stall on all $3 \mathrm{~d}$, resulting in more time spent standing on $\mathrm{d}-2$ and -1 . Cows with metritis tended to have more aborted lying events on $\mathrm{d}$
\end{abstract}

Received November 17, 2017.

Accepted April 22, 2018.

${ }^{1}$ Corresponding author: marina.vonkeyserlingk@ubc.ca
-2 , and significantly more on $\mathrm{d}-1$. Cows with metritis tended to be replaced more often at the lying stall on $d$ -3 and tended to have a longer latency to lie down on $\mathrm{d}$ -2 . We observed no differences between health groups in the number of actor replacements or the number of visits to the stall. In summary, cows with metritis spent more time standing fully in the lying stall and had more aborted lying events. These results suggest that primiparous cows with metritis may be identified by altered behavior at the lying stall.

Key words: sickness, pain, disease, welfare

\section{INTRODUCTION}

Reduced feeding, decreased social interactions, and increased resting are associated with the onset of sickness in many mammals (Dantzer and Kelley, 2007). In dairy cows, feeding behaviors and social behaviors at the feed bunk in particular have been explored, and some of these behaviors have shown promise as early indicators of disease. Compared with healthy cows, ill cows consume less DM (Huzzey et al., 2007; Fogsgaard et al., 2015), spend less time feeding (González et al., 2008; Goldhawk et al., 2009), engage in fewer competitive interactions at the feeder (Huzzey et al., 2007), and avoid the feed bunk at peak feeding times when competitive interactions are most common (SepúlvedaVaras et al., 2016).

Avoidance of social interactions by ill cows may also be evident in contexts other than feeding. For example, cows that became ill with either mastitis or metritis in the days following calving increased use of an area visually separating them from the remainder of the herd (Proudfoot et al., 2014). Freestalls do not provide visual separation, but as partitions at the feed bunk reduce competitive social interactions during feeding (DeVries and von Keyserlingk, 2006; Hetti Arachchige et al., 2014), lying stall partitions that separate animals from one another may also offer a protective environment and therefore may be more attractive when animals are ill.

Dairy cows alter lying behavior in response to sickness (Sepúlveda-Varas et al., 2014; Itle et al., 2015) and pain (Mølgaard et al., 2012). Multiple studies have 
reported shorter lying times in cows with clinical mastitis compared with healthy animals, suggesting that cows may be avoiding painful pressure on the inflamed udder (Siivonen et al., 2011; Fogsgaard et al., 2012, 2015). Previous work has found that cows experiencing painful conditions (e.g., dystocia and mastitis) lie down more often (i.e., have more lying bouts; Proudfoot et al., 2009; de Boyer des Roches et al., 2017), but other work has shown that cows with metritis lie down less often in the days before diagnosis (Neave et al., 2018). However, changes in lying time in response to disease are not always observed; for instance, cows with metritis, an infectious disease associated with visceral pain (Stojkov et al., 2015), showed no difference in lying times compared with healthy cows (Neave et al., 2018), despite showing other signs of malaise (e.g., reduced feed intake; Huzzey et al., 2007; Schirmann et al., 2016) and reduced activity (measured by neck-mounted accelerometer; Liboreiro et al., 2015). In summary, sickness and pain can both lead to behavioral changes, but these changes may differ depending upon the cause, making it difficult to predict how cows that experience both sickness and pain will respond. For example, metritis is frequently associated with a febrile response (Sheldon et al., 2006) that might be expected to increase lying time, as ill animals typically rest for prolonged periods (Hart, 1988); however, metritis is also associated with visceral pain (Stojkov et al., 2015), possibly resulting in avoidance of lying down or hindering the lying down movement.

To our knowledge, no research has investigated if cows alter their behavior in response to malaise or pain at the lying stall independently from lying times. Thus, the objective of our study was to investigate stall use, including times spent at the stall, social interactions, and lying-related behaviors, by primiparous cows diagnosed with metritis. We hypothesized that cows with metritis would increase stall usage, specifically standing in the stall, engage in fewer antagonistic interactions and show more aborted lying events in the days before diagnosis.

\section{MATERIALS AND METHODS}

Cows in our study were part of a larger project on metritis investigating the effects of parity on changes in behavior (Neave et al., 2017), sickness behavior in the days before diagnosis (Neave et al., 2018), and treatment with meloxicam (Lomb et al., 2018). The study was conducted from July 2013 to October 2014 at the University of British Columbia's Dairy Education and Research Centre in Agassiz (BC, Canada). All animals were cared for according to the Canadian Council on Animal Care (2009) and procedures were approved by the University of British Columbia's Animal Care Committee (Protocols A10-0163 and A14-0040).

\section{Housing and Management}

During the study, behaviors and the health status of all animals in the herd $(\mathrm{n}=337$ Holstein cows $)$ were monitored from approximately $3 \mathrm{wk}$ before to $3 \mathrm{wk}$ after calving. By the end of the study period, data for 105 primiparous cows had been collected.

Within $24 \mathrm{~h}$ after parturition, all cows were moved into a mixed-parity postpartum pen where they remained for a minimum of $21 \mathrm{~d}$. Whenever a freshly calved cow was introduced, the cow with the highest DIM (DIM at removal ranged from 21 to 37, with a mean of 30) was removed to maintain a stocking density of 20. On a single occasion in spring 2014, where a longer lag occurred between calving events, 8 cows with high DIM were replaced with pregnant filler cows to maintain stocking density. Feed and water were provided from 12 electronic feed bins and 2 electronic water bins, respectively (Insentec, Marknesse, Holland; validated by Chapinal et al., 2007). The lying area consisted of 24 lying stalls, equipped with mats (Pasture Mat, Promat Inc., Woodstock, ON, Canada) covered with $5 \mathrm{~cm}$ of sand. The stalls were $120 \mathrm{~cm}$ wide (center to center) and $260 \mathrm{~cm}$ long, with the brisket board placed $170 \mathrm{~cm}$ from the inside of the back curb. The neck rail was positioned at $115 \mathrm{~cm}$ above the bedded surface, $165 \mathrm{~cm}$ as measured from the horizontal axis, and $200 \mathrm{~cm}$ as measured from the diagonal axis to the inside of the back curb. Stalls were raked clean twice daily when the cows were brought up for milking, and fresh sand was added on Monday and Friday every week of the study. Concrete floors in both alleys (i.e., feed alley and the alley between lying stalls) and crossover alleys were covered with vulcanized rubber mats (Gummiwerk KRAIBURG Elastik, Tittmoning, Germany).

Cows were milked twice daily at approximately 0700 and $1700 \mathrm{~h}$. At approximately 0800 and $1600 \mathrm{~h}$, cows were provided fresh feed formulated to meet the NRC (2001) nutrient requirements. Feed samples were taken once weekly, pooled into monthly samples, and analyzed. The postpartum cow TMR included $26 \%$ corn silage, $13 \%$ grass silage, $7 \%$ alfalfa hay, $4 \%$ grass hay, and $50 \%$ grain concentrate mash $(\mathrm{DM}=50.35 \pm 2.5 \%$, $\mathrm{CP}=18.3 \pm 0.58 \% \mathrm{DM}, \mathrm{ADF}=18.1 \pm 0.71 \% \mathrm{DM}$, $\mathrm{NDF}=28.5 \pm 1.2 \% \mathrm{DM}$, and $\mathrm{NE}_{\mathrm{L}}=1.72 \pm 0.014$ $\mathrm{Mcal} / \mathrm{kg}$; described in full by Neave et al., 2017).

\section{Diagnosis of Disease}

Based on the methodology described by Huzzey et al. (2007), cows were screened for metritis on every 
third day after calving, beginning at 3 DIM and lasting until 21 DIM. For this purpose, animals were moved into a sorting area immediately after morning milking (between 0800 and $1000 \mathrm{~h}$ ) and restrained using headlocks. Metritis diagnosis was based on the visual appearance (color, consistency, presence of pus) and olfactory sensation (no odor/foul smell) of vaginal discharge using a 5-point scoring system, from 0 to 4 (described by Huzzey et al., 2007); cows with a clear, cloudy or bloody mucus and no smell were diagnosed with a healthy uterus (score 0 and 1), whereas cows with foul-smelling discharge that either contained pus or was of watery, brownish character were diagnosed with metritis (scores 2-4). On the morning of diagnosis (between 0800 and $1000 \mathrm{~h}$ ), cows with metritis were enrolled in the study described by Lomb et al. (2018), where cows were randomly treated with the nonsteroidal anti-inflammatory drug meloxicam or a placebo in addition to an antimicrobial.

Retained placenta was diagnosed when fetal membranes were still attached $24 \mathrm{~h}$ after calving. Other clinical diseases (i.e., mastitis, ketosis, displacement of abomasum) were diagnosed based on standard farm protocols or by the herd veterinarian. Calving ease was categorized as unassisted, easy pull (i.e., 1 person assisted) or dystocia (i.e., hard pull with more than 1 person assisting or malpresentation of the calf). Beginning the first day after calving, the rectal body temperature of each animal was taken daily between 0800 and 1200 $\mathrm{h}$ using a digital thermometer (Nexcare Rapid Digital Thermometer, 3M, St. Paul, MN) that was inserted $10 \mathrm{~cm}$ into the rectum and pressed against the lateral wall. All cows were weighed twice within the first $3 \mathrm{~d}$ after calving, with values averaged to provide a mean BW. Cows were categorized as healthy if they were not diagnosed with any clinical disease, including dystocia, and did not have a body temperature $>39.5^{\circ} \mathrm{C}$ more than once during the 21-d observation period.

\section{Study Animals}

All primiparous cows diagnosed with a metritis score 4 were considered for participation in the study. Out of the 26 initially eligible cows, 10 were excluded due to incomplete video records of the $3 \mathrm{~d}$ before metritis diagnosis. The remaining 16 cows were diagnosed with metritis on either DIM $6(\mathrm{n}=11), 9(\mathrm{n}=3)$, or $12(\mathrm{n}=$ 2 ), had an average BW of $574 \pm 65.3 \mathrm{~kg}$, and an average daily milk yield over the first 21 DIM postpartum of $24 \pm 4.9 \mathrm{~kg} / \mathrm{d}$.

From the healthy primiparous cows $(\mathrm{n}=42), 16$ animals were selected as match pairs to the metritic animals. The identification of the match pairs took place by first, excluding any animals with missing video data $(n=12)$. Second, of the remaining animals, healthy cows were matched with metritic cows based on BW and, when possible, calving date. Lastly, when more than 1 cow had a similar BW and calving date, selection was random. The identified 16 healthy cows had an average BW of $603 \pm 51.6 \mathrm{~kg}$ and an average daily milk yield over the first 21 DIM of $24 \pm 4.2 \mathrm{~kg} / \mathrm{d}$. With the exception of 1 healthy cow that had a metritis score of 0 , the remaining 15 healthy animals all had a metritis score of 1 .

\section{Behavioral Measures}

All behaviors were assessed by video. Four cameras (CCTV camera, model WVCW504SP, Panasonic, Osa$\mathrm{ka}$, Japan) were mounted $6 \mathrm{~m}$ above the experimental pen, 2 above the feed alley and 2 above the lying stalls. Cameras were connected to a digital video surveillance system (GeoVision, GeoVision Inc., Corona, CA). Cows were marked on their back and sides with alphanumeric symbols using hair dye to allow for individual identification.

Behaviors of metritic cows were assessed on the $3 \mathrm{~d}$ before diagnosis ( $\mathrm{d}-3$ to -1 ), before any treatment was given to the participating cows (Lomb et al., 2018). The 3-d window for behavioral observations was chosen given that cows were scored as clinically healthy (nonmetritic) during the health check $3 \mathrm{~d}$ before metritis diagnosis. For healthy animals, the 3 corresponding DIM to the metritic pair were analyzed. To account for the time of diagnosis, days were adjusted to start at $1000 \mathrm{~h}$; for example, $\mathrm{d}-1$ included the 24 -h interval from $1000 \mathrm{~h}$ on the day before diagnosis to $1000 \mathrm{~h}$ on the day of diagnosis.

Behaviors were scored by 3 trained observers, and agreement was tested using Cohen's kappa (Cohen, 1960). Observers reached excellent inter- and intraobserver agreement ( $\kappa>0.75$; Kaufman and Rosenthal, 2009 ) for all reported behaviors. One of these observers, blind to health status of the animal, scored all aborted lying events.

Position and Time Spent in the Stall. The overall time each cow spent at the lying stall, as well as the positions she adopted in the stall, was measured using 5 -min scan samples. The specific positions recorded were lying, with abdomen touching the ground; perching, with 2 front feet in the stall; and standing fully in stall, with all 4 feet in the stall. If at the moment of the scan the cow was changing her position, the position she adopted at the end of the movement was recorded.

The duration of each behavior in minutes per day was estimated by multiplication of the number of scans by 5 (the length of the sampling interval, described and validated for standing behavior in cattle by Chen 
et al., 2016). Reported are lying time ( $\mathrm{min} / \mathrm{d})$, time spent perching $(\mathrm{min} / \mathrm{d})$, time standing fully in the stall $(\mathrm{min} / \mathrm{d})$, time spent standing in the stall $(\mathrm{min} / \mathrm{d})$, and total time at the stall $(\mathrm{min} / \mathrm{d})$. The total time standing in the stall was defined as the sum of time spent perching and standing fully in the stall. The total time at the stall was defined as the sum of lying and standing time in either position in the stall.

Social Behavior. Social behaviors at the lying stalls were observed by continuous assessment of the video. Social interactions at lying stalls included actor replacement, when the focal cow used physical contact (e.g., head butt, push) to force another cow out of the stall, and thereafter either entered the stall or remained outside the stall; and reactor replacement, when the focal cow was forced out of the stall by physical contact (e.g., head butt, push) from another cow. The position of the reactor cow (lying, perching, or standing fully in the stall) at the time of displacement was also noted for each event. The number of times she was replaced out of either a lying or standing position was calculated in relation to the time she spent in that position (i.e., number of position replacements/h spent in this position).

Lying-Associated Behaviors. Continuous observations were also used to assess behaviors related to lying down. To lie down in the stall, a cow must enter with all 4 feet. Once she had entered a stall, we recorded either a (1) visit, when the cow left without lying down, or (2) an aborted lying event, when the cow displayed behaviors associated with lying down but did not do so. An aborted lying event was recorded when the cow (1) completed at least 1 sweeping head movement (Österman and Redbo, 2001) that crossed her centerline while lowering her head to the ground (Tucker and Weary, 2004); (2) completed a minimum of 2 steps or leg movements toward the center of her body (underneath) while her head was lowered to the ground; or (3) lowered herself from a standing position to her carpal joints but then moved back into the standing position without lying down.

When cows actually completed the lying down movement, the latency to lie down was recorded as the time from the first aborted lying event until she successfully lay down; intervals that precluded stall use (e.g., milking, sand delivery) were not included. We report the daily number of visits to the lying stalls, the daily number of aborted lying events, and the average latency to lie down (min/lying bout).

\section{Statistical Analyses}

All statistical analyses were performed using SAS (Version 9.4; SAS Institute Inc., Cary, NC), with cow as experimental unit and behaviors summarized per cow and day. Variables were screened by health group using PROC UNIVARIATE. Four variables (standing fully in the stall, reactor replacements when standing fully in the stall, aborted lying events, and average latency to lie down) were transformed using the $\log _{10^{-}}$ transformation to normalize distributions for further analyses.

Behavioral differences between healthy and metritic cows were analyzed using PROC MIXED in SAS. The initial model included BW (kg), DIM at diagnosis (diagnosis day; 3 levels: 6, 9, and 12), and health status (2 levels: healthy vs. metritis) as between-cow factors, and day relative to diagnosis (observation day; 3 levels: $\mathrm{d}-3, \mathrm{~d}-2$ and $\mathrm{d}-1$ ) as a within-cow factor. The interaction of health status with observation day was also offered to the model; this interaction was evident (with $P \leq 0.10$ ) for 2 of the outcome variables (standing fully in the stall and reactor replacements). Hence, all analyses were performed by observation day, with $\mathrm{BW}$, diagnosis day, and health status as covariates in the model.

Results for normally distributed variables are presented as least squares means and standard errors. Results for variables that were $\log _{10}$-transformed are reported as back-transformed geometric means and $95 \%$ confidence interval on the original scale. The significance level was set at $P<0.05$ and tendencies are reported when $P \leq 0.10$.

We observed a low frequency of replacements out of a lying position [metritis $=0(0-0.33)$; healthy $=0.17$ (0-0.33) no./60 min; median (Q1 - Q3)]. Therefore, treatment differences were not tested for this measure. Differences in lying time and daily number of lying bouts were previously reported by Neave et al. (2018), where cows with metritis had fewer, but longer lying bouts; these measures are only reported here when necessary to supplement outcome measures of interest.

\section{RESULTS}

On $\mathrm{d}-2$, cows diagnosed with metritis tended to spend more time standing in the stall than healthy cows $\left(F_{1,28}=3.62, P=0.07\right)$; the difference was more pronounced on d $-1\left(F_{1,28}=8.92, P<0.01\right.$; Table 1$)$. This difference was driven by an increase in standing fully in the stall by metritic animals $\left(\mathrm{d}-3: F_{1,28}=4.31\right.$, $P<0.05 ; \mathrm{d}-2: F_{1,28}=15.9, P<0.001 ; \mathrm{d}-1: F_{1,28}=$ 21.77, $P<0.001$; Figure 1) on all $3 \mathrm{~d}$ before diagnosis. We observed no differences between the health groups in time spent perching and the total time spent at the stall.

We found no difference in the number of actor replacements between healthy and metritic cows, but noted a 
EFFECTS OF METRITIS ON BEHAVIOR AT THE LYING STALL

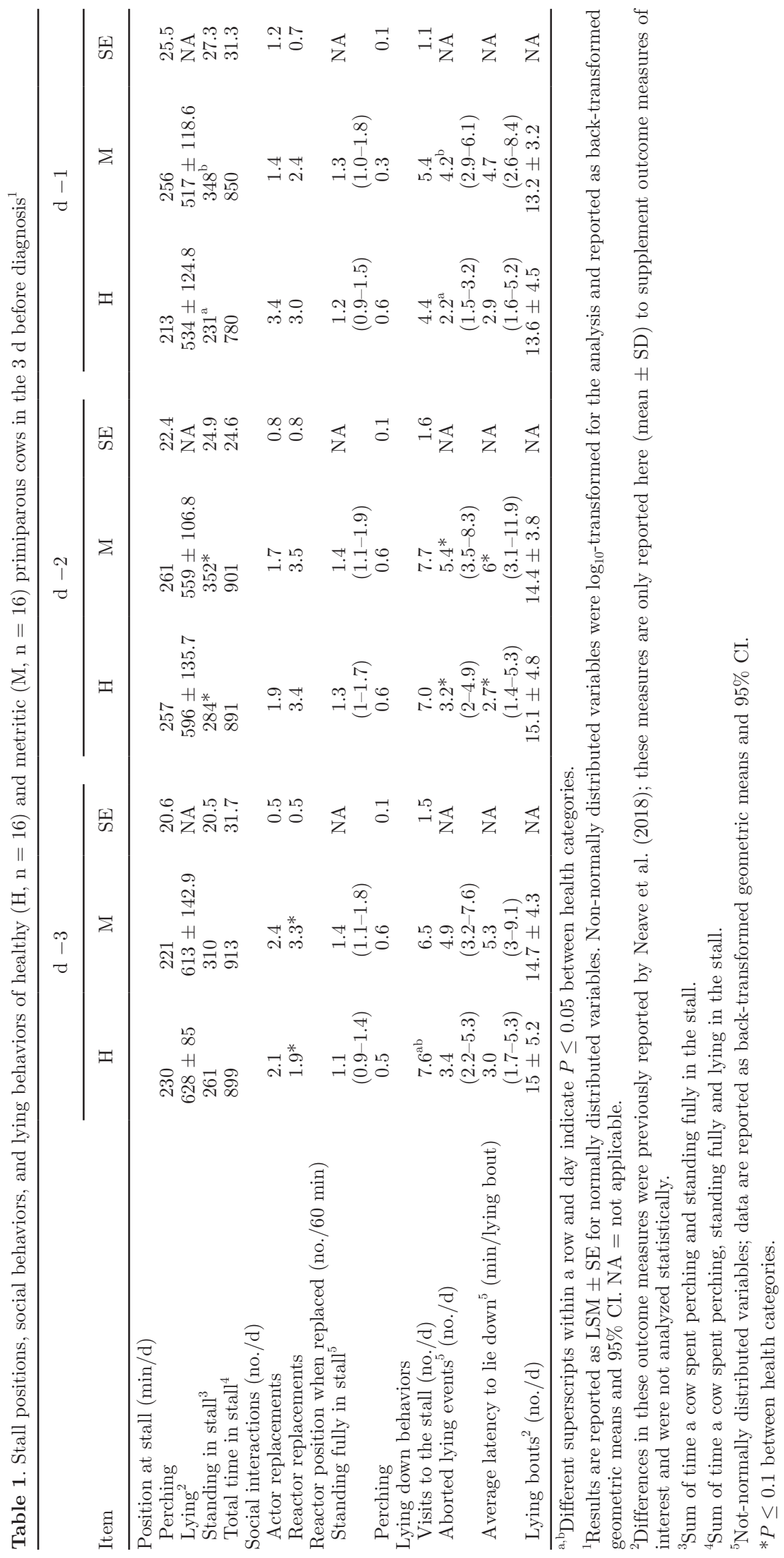




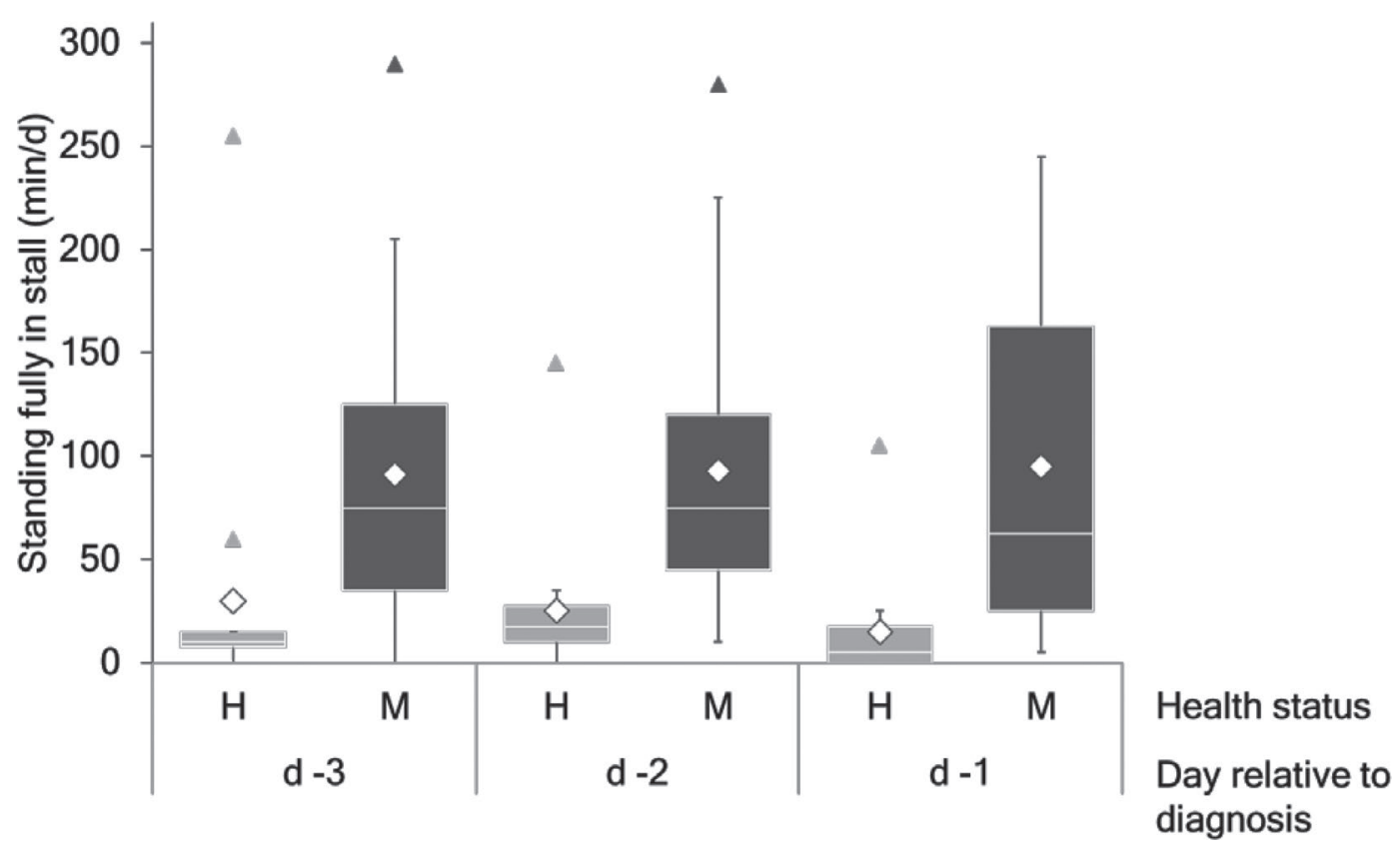

Figure 1. Standing fully in the stall in metritic $(\mathrm{M}, \mathrm{n}=16)$ versus healthy $(\mathrm{H}, \mathrm{n}=16)$ primiparous dairy cows in the $3 \mathrm{~d}$ before diagnosis. Whiskers show $1.5 \times$ interquartile range, boxes show interquartile range, the white line shows the median, the open diamonds show the mean, and the filled triangles show outliers (in the healthy cow group, the outlier was to the same cow on all $3 \mathrm{~d}$ and in the metritic cow group the outliers are from 2 different cows).

tendency on $\mathrm{d}-3$ for healthy cows to be replaced less often $\left(F_{1,28}=3.59, P=0.07\right)$. Cows were displaced out of the 2 standing positions (perching and standing fully in the stall) at similar frequencies.

Cows with metritis tended to have a higher number of aborted lying events compared with their healthy counterparts on $\mathrm{d}-2\left(F_{1,28}=2.99, P=0.09\right)$ and had more aborted lying events on $\mathrm{d}-1\left(F_{1,28}=5.9, P<\right.$ $0.05)$. Cows with metritis also tended to have longer average latencies to lie down than healthy cows on $\mathrm{d}$ $-2\left(F_{1,28}=2.84, P=0.1\right)$. Healthy and metritic cows did not differ in the number of visits to the lying stall.

\section{DISCUSSION}

As predicted, primiparous cows diagnosed with metritis spent more time standing in the stall. This difference became more pronounced over the 3 -d observation period, possibly due to the progression of metritis. The difference in standing time in the stall was driven by prolonged standing with all 4 feet in the stall by the metritic cows. Previous work has shown that standing in the stall with all 4 feet is dependent on stall design (Tucker and Weary, 2004; Tucker et al., 2005); for example, when the neck rail is placed in a less restrictive position, at $190 \mathrm{~cm}$ distance to the rear curb, cows increase the time they spend standing fully in the stall (Fregonesi et al., 2009). Interestingly, Fregonesi et al. (2009) reported that the early-lactation healthy cows used in their study only spent approximately 36 $\mathrm{min} / \mathrm{d}$ engaged in this behavior. In contrast, the sick primiparous cows in our study stood more than twice as long with 4 feet in the stall, despite the presence of a more restrictively placed neck rail $(165 \mathrm{~cm}$ from the rear curb, horizontally measured). This difference is consistent with the idea that cows with metritis are more highly motivated to perform this behavior.

One response to sickness in social animals is selfisolation (Hart 1988). Proudfoot et al. (2014) reported that, in contrast to healthy cows, freshly calved dairy cows diagnosed with mastitis or metritis spent more time behind a plywood board that provided a visual barrier from the herd. Similarly, sick calves were found to lie down further away from pen mates than healthy ones (Cramer and Stanton, 2015; Cramer et al., 2016). Cows in our study were not able to visually or physically separate themselves from the group, but spending time standing in the stall may have provided some form of protection. DeVries and von Keyserlingk (2006) and Jensen et al. (2008) provide evidence that partitions at the feeder reduce competitive behaviors in cows and calves, respectively. We suggest that the increased time spent standing fully in the stall can be viewed as a type of self-isolation sickness behavior. However, given the influence of stall design on this behavior, future work is needed to investigate how stall dimensions and cow 
size influence this change in behavior. In addition, we may have gained a better understanding of when stall standing behaviors change in relation to clinical symptoms with a daily examination of vaginal discharge as opposed to the 3 -d interval.

Ill animals typically increase resting time, likely to conserve energy and support the systemic response to infection (Hart, 1988). However, as reported in our previous paper (Neave et al., 2018), we noted no differences in lying time between metritic and healthy cows. We hypothesized that this might be a consequence of the sick cows being hesitant to lie down, possibly in response to visceral pain (Stojkov et al., 2015), as longer standing times have also been reported after liver biopsy (Mølgaard et al., 2012) and ruminal acidosis (DeVries et al., 2009). We therefore predicted that metritic cows would show more behaviors indicating a reluctance to lie down, as measured by aborted lying events. Similar abnormal lying down movements as described in our study have been used by others to measure stall comfort (Krohn and Munksgaard, 1993; Tucker and Weary, 2004; Dippel et al., 2009), as well as responses to different milking regimens (Österman and Redbo, 2001) and oligofructose overload (Niss et al., 2009). We suggest that pain due to lying down may explain the health group differences in the current study, especially because these differences became more pronounced with time. Visceral inflammatory pain can be referred to other viscera or somatic areas (viscerovisceral or viscero-somatic pain; Gebhart and Bielefeldt, 2016). Visceral pain and viscero-visceral pain likely contributed to increased back arch during transrectal uterine palpation in metritic versus healthy cows (Stojkov et al., 2015). In the current study, referred pain to the viscera may have resulted in pain during lying movements that put tension or pressure on the viscera. Visceral pain may have also led to somatic hyperalgesia (e.g., Wesselmann and Lai, 1997), making skin areas sensitive to touch during lying movements and when lying. We encourage future studies to include measures of hyperalgesia in dairy cows with uterine infection.

The observed reluctance to lie down, measured by aborted lying events, may explain why primiparous cows with metritis had shorter lying times than expected given their illness (Neave et al., 2018). This may also have contributed to the increase in standing fully in the stall by animals with metritis; despite no differences in latencies to lie down, metritic cows may have initially searched for a suitable lying space but then remained standing in the stall.

Avoidance of competitive interactions at the feed bunk has been reported in dairy cows before diagnosis with metritis and mastitis (Huzzey et al., 2007; Sepúlveda-Varas et al., 2016), providing the basis for our prediction that metritic cows would take part in fewer agonistic interactions at the lying stalls. However, we found little evidence of a difference between health groups. The high number of actor replacements in ill cows in our study may be explained by increased motivation of these animals to access the lying stalls, resulting in increased time spent fully standing in the stall.

The combined number of actor and reactor displacements from the lying stalls in the current study was higher than that reported by others using similar stocking densities (Fregonesi et al., 2007; Val-Laillet et al., 2008; Winckler et al., 2015). These previous studies used mid-lactation, healthy cows housed in stable groups. The higher replacement rate in our study may be explained by the frequent regrouping due to the dynamic group structure. In addition, we only observed primiparous cows that were likely at greater risk of being replaced than multiparous animals as these animals likely had a lower rank within the group hierarchy. Wierenga (1990) reported that younger cows were replaced more often at the feeder and at the lying stalls. Interestingly, standing in the stall in either position (perching or standing fully in the stall) did not seem to provide protection for the cows with metritis, given that they were displaced similarly often as healthy cows. A growing body of literature describes behavioral changes before diagnosis of clinical disease in dairy cows, but much of this focuses on DMI and feeding behaviors. With the development of technology that allows for real-time tracking of cow location within the pen (Meunier et al., 2017; Wolfger et al., 2017) and real-time detection of lying behavior (Porto et al., 2013), it is now also feasible to use behavioral changes at the lying stalls.

\section{CONCLUSIONS}

Metritic cows spent more time standing in the stall. Behavioral differences may have been part of a general response to sickness or may be specifically associated with pain, as suggested by an increased number of aborted lying events. Our findings suggest that increased times standing in the stall may be helpful in identifying sick dairy cows.

\section{ACKNOWLEDGMENTS}

We thank all the staff and students of the University of British Columbia (UBC) Dairy Education and Research Centre who helped with data collection in this experiment. We are particularly grateful to Julie Huzzey, Sara McNamara, and Bianca Costa. We thank Boehringer Ingelheim Animal Health (Burlington, Ontario, Canada) for their generous donation to support 
the various students that helped with this trial. General funding for UBC's Animal Welfare Program comes from an NSERC Industrial Research Chair with industry contributions from the Dairy Farmers of Canada (Ottawa, ON, Canada), British Columbia Dairy Association (Burnaby, BC Canada), Westgen Endowment Fund (Milner, BC, Canada), Intervet Canada Corporation (Kirkland, QC, Canada), Novus International Inc. (Oakville, ON, Canada), Zoetis (Kirkland, QC, Canada), BC Cattle Industry Development Fund (Kamloops, BC, Canada), Alberta Milk (Edmonton, AB, Canada), Valacta (St. Anne-de-Bellevue, QC, Canada), and CanWest DHI (Guelph, ON, Canada).

\section{REFERENCES}

CCAC (Canadian Council on Animal Care). 2009. CCAC Guidelines on the Care and Use of Farm Animals in Research, Teaching and Testing, Canadian Counc. Anim. Care, Ottawa, ON, Canada.

Chapinal, N., D. M. Veira, D. M. Weary, and M. A. G. von Keyserlingk. 2007. Technical note: Validation of a system for monitoring individual feeding and drinking behavior and intake in group-housed cattle. J. Dairy Sci. 90:5732-5736. https://doi.org/ 10.3168/jds.2007-0331.

Chen, J. M., K. E. Schütz, and C. B. Tucker. 2016. Technical note: Comparison of instantaneous sampling and continuous observation of dairy cattle behavior in freestall housing. J. Dairy Sci. 99:8341-8346. https://doi.org/10.3168/jds.2016-11351.

Cohen, J. 1960. A coefficient of agreement for nominal scales. Educ. Psychol. Meas. 20:37-46.

Cramer, M. C., T. L. Ollivett, and A. L. Stanton. 2016. Associations of behavior-based measurements and clinical disease in preweaned, group-housed dairy calves. J. Dairy Sci. https://doi.org/10.3168/ jds.2015-10207.

Cramer, M. C., and A. L. Stanton. 2015. Associations between health status and the probability of approaching a novel object or stationary human in preweaned group-housed dairy calves. J. Dairy Sci. 98:7298-7308. https://doi.org/10.3168/jds.2015-9534.

Dantzer, R., and K. W. Kelley. 2007. Twenty years of research on cytokine-induced sickness behavior. Brain Behav. Immun. 21:153-160. https://doi.org/10.1016/j.bbi.2006.09.006.

de Boyer des Roches, A., M. Faure, A. Lussert, V. Herry, P. Rainard, D. Durand, and G. Foucras. 2017. Behavioral and patho-physiological response as possible signs of pain in dairy cows during Escherichia coli mastitis: A pilot study. J. Dairy Sci. 100:8385-8397. https://doi.org/10.3168/jds.2017-12796.

DeVries, T. J., K. A. Beauchemin, F. Dohme, and K. S. SchwartzkopfGenswein. 2009. Repeated ruminal acidosis challenges in lactating dairy cows at high and low risk for developing acidosis: Feeding, ruminating, and lying behavior. J. Dairy Sci. 92:5067-5078. https://doi.org/10.3168/jds.2009-2102.

DeVries, T. J., and M. A. G. von Keyserlingk. 2006. Feed stalls affect the social and feeding behavior of lactating dairy cows. J. Dairy Sci. 89:3522-3531. https://doi.org/10.3168/jds.S0022 -0302(06)72392-X.

Dippel, S., M. Dolezal, C. Brenninkmeyer, J. Brinkmann, S. March, U. Knierim, and C. Winckler. 2009. Risk factors for lameness in freestall-housed dairy cows across two breeds, farming systems, and countries. J. Dairy Sci. 92:5476-5486. https://doi.org/10 $.3168 /$ jds.2009-2288.

Fogsgaard, K. K., T. W. Bennedsgaard, and M. S. Herskin. 2015. Behavioral changes in freestall-housed dairy cows with naturally occurring clinical mastitis. J. Dairy Sci. 98:1730-1738. https://doi .org/10.3168/jds.2014-8347.

Fogsgaard, K. K., C. M. Røntved, P. Sørensen, and M. S. Herskin. 2012. Sickness behavior in dairy cows during Escherichia coli mas- titis. J. Dairy Sci. 95:630-638. https://doi.org/10.3168/jds.2011 -4350 .

Fregonesi, J. A., C. B. Tucker, and D. M. Weary. 2007. Overstocking reduces lying time in dairy cows. J. Dairy Sci. 90:3349-3354. https://doi.org/10.3168/jds.2006-794.

Fregonesi, J. A., M. A. G. von Keyserlingk, C. B. Tucker, D. M. Veira, and D. M. Weary. 2009. Neck-rail position in the free stall affects standing behavior and udder and stall cleanliness. J. Dairy Sci. 92:1979-1985. https://doi.org/10.3168/jds.2008-1604.

Gebhart, G. F., and K. Bielefeldt. 2016. Physiology of visceral pain. Compr. Physiol. 6:1609-1633. https://doi.org/10.1002/cphy .c150049.

Goldhawk, C., N. Chapinal, D. M. Veira, D. M. Weary, and M. A. G. von Keyserlingk. 2009. Prepartum feeding behavior is an early indicator of subclinical ketosis. J. Dairy Sci. 92:4971-4977. https:// doi.org/10.3168/jds.2009-2242.

González, L. A., B. J. Tolkamp, M. P. Coffey, A. Ferret, and I. Kyriazakis. 2008. Changes in feeding behavior as possible indicators for the automatic monitoring of health disorders in dairy cows. J. Dairy Sci. 91:1017-1028. https://doi.org/10.3168/jds.2007-0530.

Hart, B. L. 1988. Biological basis of the behavior of sick animals. Neurosci. Biobehav. Rev. 12:123-137. https://doi.org/10.1016/S0149 -7634(88)80004-6.

Hetti Arachchige, A. D., A. D. Fisher, W. J. Wales, M. J. Auldist, M. C. Hannah, and E. C. Jongman. 2014. Space allowance and barriers influence cow competition for mixed rations fed on a feed-pad between bouts of grazing. J. Dairy Sci. 97:3578-3588. https://doi .org/10.3168/jds.2013-7553.

Huzzey, J. M., D. M. Veira, D. M. Weary, and M. A. G. von Keyserlingk. 2007. Prepartum behavior and dry matter intake identify dairy cows at risk for metritis. J. Dairy Sci. 90:3220-3233. https:// doi.org/10.3168/jds.2006-807.

Itle, A. J., J. M. Huzzey, D. M. Weary, and M. A. G. von Keyserlingk. 2015. Clinical ketosis and standing behavior in transition cows J. Dairy Sci. 98:128-134. https://doi.org/10.3168/jds.2014-7932.

Jensen, M. B., A. M. de Passillé, M. A. G. von Keyserlingk, and J. Rushen. 2008. A barrier can reduce competition over teats in pair-housed milk-fed calves. J. Dairy Sci. 91:1607-1613. https:// doi.org/10.3168/jds.2007-0623.

Kaufman, A. B., and R. Rosenthal. 2009. Can you believe my eyes? The importance of interobserver reliability statistics in observations of animal behaviour. Anim. Behav. 78:1487-1491. https:// doi.org/10.1016/j.anbehav.2009.09.014.

Krohn, C. C., and L. Munksgaard. 1993. Behaviour of dairy cows kept in extensive (loose housing/pasture) or intensive (tie stall) environments II. Lying and lying-down behaviour. Appl. Anim. Behav. Sci. 37:1-16. https://doi.org/10.1016/0168-1591(93)90066-X.

Liboreiro, D. N., K. S. Machado, P. R. B. Silva, M. M. Maturana, T. K. Nishimura, A. P. Brandão, M. I. Endres, and R. C. Chebel. 2015. Characterization of peripartum rumination and activity of cows diagnosed with metabolic and uterine diseases. J. Dairy Sci. 98:6812-6827. https://doi.org/10.3168/jds.2014-8947.

Lomb, J., H. W. Neave, D. M. Weary, S. J. LeBlanc, J. M. Huzzey, and M. A. G. von Keyserlingk. 2018. Changes in feeding, social, and lying behaviors in dairy cows with metritis following treatment with a nonsteroidal anti-inflammatory drug as adjunctive treatment to an antimicrobial. J. Dairy Sci. 101:4400-4411. https://doi.org/10 $.3168 /$ jds.2017-13812.

Meunier, B., P. Pradel, K. H. Sloth, C. Cirié, E. Delval, M. M. Mialon, and I. Veissier. 2017. Image analysis to refine measurements of dairy cow behaviour from a real-time location system. Biosyst. Eng. https://doi.org/10.1016/J.BIOSYSTEMSENG.2017.08.019.

Mølgaard, L., B. M. Damgaard, V. Bjerre-Harpøth, and M. S. Herskin. 2012. Effects of percutaneous needle liver biopsy on dairy cow behaviour. Res. Vet. Sci. 93:1248-1254. https://doi.org/10.1016/ j.rvsc.2012.04.001.

Neave, H. W., J. Lomb, M. A. G. von Keyserlingk, A. Behnam-Shabahang, and D. M. Weary. 2017. Parity differences in the behavior of transition dairy cows. J. Dairy Sci. 100:548-561. https://doi.org/ 10.3168/jds.2016-10987. 
Neave, H. W., J. Lomb, D. M. Weary, S. J. LeBlanc, J. M. Huzzey, and M. A. G. von Keyserlingk. 2018. Behavioral changes before metritis diagnosis in dairy cows. J. Dairy Sci. 101:4388-4399. https:// doi.org/10.3168/jds.2017-13078.

Niss, D. B., M. S. Herskin, A. M. Danscher, and M. B. Thoefner. 2009. Short communication: Rising and lying behavior of heifers before and after alimentary oligofructose overload. J. Dairy Sci. 92:617-620.

NRC. 2001. Nutrient Requirements of Dairy Cattle. 7th rev. Natl. Acad. Sci., Washington, DC.

Österman, S., and I. Redbo. 2001. Effects of milking frequency on lying down and getting up behaviour in dairy cows. Appl. Anim. Behav. Sci. 70:167-176. https://doi.org/10.1016/S0168-1591(00)00159-3.

Porto, S. M. C., C. Arcidiacono, U. Anguzza, and G. Cascone. 2013. A computer vision-based system for the automatic detection of lying behaviour of dairy cows in free-stall barns. Biosyst. Eng. 115:184194. https://doi.org/10.1016/J.BIOSYSTEMSENG.2013.03.002.

Proudfoot, K. L., J. M. Huzzey, and M. A. G. von Keyserlingk. 2009 The effect of dystocia on the dry matter intake and behavior of Holstein cows. J. Dairy Sci. 92:4937-4944. https://doi.org/10 $.3168 /$ jds.2009-2135.

Proudfoot, K. L., M. B. Jensen, D. M. Weary, and M. A. G. von Keyserlingk. 2014. Dairy cows seek isolation at calving and when ill. J. Dairy Sci. 97:2731-2739. https://doi.org/10.3168/jds.2013-7274.

Schirmann, K., D. M. Weary, W. Heuwieser, N. Chapinal, R. L. A. Cerri, and M. A. G. von Keyserlingk. 2016. Short communication: Rumination and feeding behaviors differ between healthy and sick dairy cows during the transition period. J. Dairy Sci. 99:99179924. https://doi.org/10.3168/jds.2015-10548.

Sepúlveda-Varas, P., K. L. Proudfoot, D. M. Weary, and M. A. G. von Keyserlingk. 2016. Changes in behaviour of dairy cows with clinical mastitis. Appl. Anim. Behav. Sci. 175:8-13. https://doi.org/10 .1016/j.applanim.2014.09.022.

Sepúlveda-Varas, P., D. M. Weary, and M. A. G. von Keyserlingk. 2014. Lying behavior and postpartum health status in grazing dairy cows. J. Dairy Sci. 97:6334-6343. https://doi.org/10.3168/ jds.2014-8357.

Sheldon, I. M., G. S. Lewis, S. LeBlanc, and R. O. Gilbert. 2006 Defining postpartum uterine disease in cattle. Theriogenology
65:1516-1530. https://doi.org/10.1016/j.theriogenology.2005.08 .021 .

Siivonen, J., S. Taponen, M. Hovinen, M. Pastell, B. J. Lensink, S. Pyörälä, and L. Hänninen. 2011. Impact of acute clinical mastitis on cow behaviour. Appl. Anim. Behav. Sci. 132:101-106. https:// doi.org/10.1016/j.applanim.2011.04.005.

Stojkov, J., M. A. G. von Keyserlingk, J. N. Marchant-Forde, and D. M. Weary. 2015. Assessment of visceral pain associated with metritis in dairy cows. J. Dairy Sci. 98:5352-5361. https://doi.org/10 $.3168 /$ jds.2014-9296.

Tucker, C. B., and D. M. Weary. 2004. Bedding on geotextile mattresses: How much is needed to improve cow comfort? J. Dairy Sci 87:2889-2895. https://doi.org/10.3168/jds.S0022-0302(04)73419 $-0$.

Tucker, C. B., D. M. Weary, and D. Fraser. 2005. Influence of neckrail placement on free-stall preference, use, and cleanliness. J. Dairy Sci. 88:2730-2737. https://doi.org/10.3168/jds.S0022 -0302(05)72952-0.

Val-Laillet, D., D. M. Veira, and M. A. G. von Keyserlingk. 2008. Short communication: Dominance in free-stall-housed dairy cattle is dependent upon resource. J. Dairy Sci. 91:3922-3926. https:// doi.org/10.3168/jds.2008-1332.

Wesselmann, U., and J. Lai. 1997. Mechanisms of referred visceral pain: Uterine inflammation in the adult virgin rat results in neurogenic plasma extravasation in the skin. Pain 73:309-317. https:// doi.org/10.1016/S0304-3959(97)00112-7.

Wierenga, H. K. 1990. Social dominance in dairy cattle and the influences of housing and management. Appl. Anim. Behav. Sci. 27:201-229. https://doi.org/10.1016/0168-1591(90)90057-K.

Winckler, C., C. B. Tucker, and D. M. Weary. 2015. Effects of under- and overstocking freestalls on dairy cattle behaviour. Appl. Anim. Behav. Sci. 170:14-19. https://doi.org/10.1016/j.applanim .2015.06.003.

Wolfger, B., B. W. Jones, K. Orsel, and J. M. Bewley. 2017. Technical note: Evaluation of an ear-attached real-time location monitoring system. J. Dairy Sci. 100:2219-2224. https://doi.org/10.3168/jds .2016-11527. 